\title{
Should the Euro Area Be Concerned About Deflation?
}

During the past few years, headline inflation (the change in the harmonised consumer price index, $\mathrm{HCPI}$ ) in the euro area has fallen steadily, from three per cent at the end of 2011 to 0.7 per cent in April 2014. It is now far below the ECB's target rate of inflation of below, but close to, two per cent. Part of the recent decline in inflation across the euro area is a temporary phenomenon - mainly the result of falling energy prices. But core inflation shows a similar trend, falling from two per cent at end-2011 to 1.1 per cent in April 2014. More worryingly, inflation expectations (according to the ECB survey of professional forecasters) have also been falling recently: in Q2 2014, the two-year ahead mean forecast is now just 1.4 per cent (compared to 1.9 per cent in 2011). Even the five-year forecast, which has been well anchored at two per cent for a long time, recently declined to 1.8 per cent. Some argue that falling prices can be a good thing, allowing us simply to buy more stuff. Others warn of the risk of a negative deflationary spiral, driving the euro area into a great depression similar to that observed in the early 1930s, with consumers anxiously postponing consumption and firms cutting down on investment, thus reinforcing an accelerating decline in the price level.

Both sides miss the point: the decline in the price level in some parts of the euro area is the result of a lack of demand due to a deep recession following the financial crisis. With unemployment and real debt rising steadily, people in these regions simply cannot afford to buy more stuff. In other parts of the euro area, the economy is booming: in Germany, the unemployment rate has come down to a level not seen since the unification boom in 1991. There is no sign that German workers postpone the purchase of durable consumption goods, expecting a steady decline of prices.

Right now, there is no need to fear a deflationary spiral. Even in Japan, with inflation rates hovering around zero per cent for more than 20 years, such a devastating spiral has not been triggered. But this is not good news: even well anchored long-term inflation expectations (between 1999 and 2013, expectations stayed consistently more than one percentage point above the actual average rate of inflation) did not help to prevent the Japanese economy from suffering two lost decades. Persistently low rates of inflation are sufficient reason to be worried.

What we really need to be concerned about is that, despite fairly good times in the core countries, the target rate of two per cent across the euro area for core inflation has been missed for more than two years, with no visible sign of a reversal of the negative trend. Even in the boom areas, both overall and core inflation stay significantly below two per cent (with 1.1 per cent HCPI and 1.6 per cent core inflation in April 2014 in Germany). As long as overall euro area inflation is too low, monetary policy is simply too tight to help to smooth the internal adjustment process urgently needed within the euro area. Instead, it severely hampers adjustment and recovery. With output below potential since the start of the financial crisis, complacency with falling rates of inflation creates the risk of one or even more lost decades.

The reason is straightforward: relative prices and wages within the euro area need to adjust to make periphery countries more competitive. Let us try a simple thought experiment and assume that core and periphery countries each carry a weight of one-half within the whole area. With wages and prices falling by two per cent in periphery countries, wage and price inflation in the core countries need to rise to six per cent in order to 
achieve the overall target of two per cent inflation. As long as, even in the core countries, average inflation is stuck around one per cent, this puts severe additional pressure on wages and prices to fall in the crisis countries. There have already been dramatic cuts in real wages implemented in the public sector in many periphery countries. But there is ample evidence that negative nominal wage adjustments in the private sector are extremely hard to enforce. It is much easier to implement cuts in real wages via inflation, while keeping nominal wages constant. In a fast growing economy, not raising wages allows for a smooth adjustment process. But as growth in the euro area is stagnating, the lower the overall rate of inflation, the longer adjustment will take, threatening to reinforce a process of long run stagnation.

But challenges in the euro area are even more dramatic: falling wages and prices aggravate the real burden of debt, resulting in severe losses for debtors. High real rates make it increasingly difficult to service the debt - the more so since most private loans and interest rates were locked in at a time when inflation expectations were well anchored around two per cent. In some crisis countries, like Ireland, Spain and Portugal, indebtedness of private households even exceeds that of the public sector. Debt deflation puts enormous strain on consumption in these countries at a time when unemployment rates are soaring. Of course, unexpectedly low rates of inflation may result in gains for creditors. But that is true only as long as the debt is likely to be repaid. As the rising real debt burden increases the risk of defaults in the periphery, creditors in the core countries may turn out to be the losers from this development.

So there are good (or rather bad) reasons to be concerned about inflation being too low in the euro area. The tricky part is how to fight low inflation. With interest rates already close to zero, standard monetary policy virtually ceases to be effective. The ECB may be inclined to charge negative interest rates for banks holding excess reserves. But apart from working as a signalling device, the impact of this measure is likely to be fairly limited. Rather than stimulating credit to the private sector in the periphery countries, banks may be inclined to reduce excess liquidity, shrinking the expansion of ECB's balance sheet even more. Since 2007, other central banks (the Fed, the Bank of England, the Swiss National Bank and recently even the Bank of Japan) have expanded their balance sheet much more forcefully than the ECB. In all these countries, unconventional monetary policy via massive quantitative easing helped to stabilise inflation without triggering inflationary spirals.

Apart from political resistance to such measures, the specific structure in the euro area (the lack of a central fiscal counterpart for the ECB and the resulting absence of "safe assets" - government debt issued by a central fiscal agency that a central bank can buy and sell without any credit risk) imposes tough limits on the feasibility of unconventional policy measures. Given this structure, there are strong incentives for the ECB to avoid potential fiscal risks. This creates a natural tendency to act too cautiously. Unfortunately, however, not acting is likely to impose fiscal risks that are even larger. For that reason, decisive actions are needed to combat the risk of too low euro area-wide inflation.

Gerhard Illing, Ludwig Maximilian University of Munich, Germany.
Since one key problem is the weakness of the banking sector across the euro area, a promising way out is to do quantitative easing by stimulating the market for securitised loans to small and medium-sized enterprises (SMEs). Committing to buy securitised loans to SMEs from institutions like the European Investment Bank and the Kreditanstalt für Wiederaufbau would encourage them to create a deep market for asset-backed securities and so could be a trigger for economic recovery. If such a move is communicated as a clear commitment to bring inflation closer to target, it may be enough to halt downward price pressures, putting a credible backstop in place. 